\title{
Neoplastic disorders of prostate glands in the light of synchrotron radiation and multivariate statistical analysis
}

\author{
A. Banas $\cdot$ K. Banas $\cdot$ W. M. Kwiatek • \\ M. Gajda • B. Pawlicki $\cdot$ T. Cichocki
}

Received: 9 March 2011 / Accepted: 12 June 2011/Published online: 26 June 2011

(C) The Author(s) 2011. This article is published with open access at Springerlink.com

\begin{abstract}
The prostate gland is the most common site of neoplastic disorders in men. The pathogenesis of inflammatory cells, prostatic intraepithelial neoplasia (PIN) lesions, and prostate cancer is still under investigation. Inflammatory cells by producing free radicals are considered as major and universal contributors to cancerogenesis. PIN is regarded as a precursor lesion to prostate cancer or a marker signaling the vulnerability of the epithelium to neoplastic transformation [1]. Differentiation markers that are frequently changed in early invasive carcinoma are also changed in PIN lesions. In this study, prostate tissue samples obtained during surgical operation and classified as various disease states (inflammation, PIN lesions, and cancer) were examined. The samples were measured by means of microbeam synchrotron-radiation-induced X-ray
\end{abstract}

\author{
A. Banas - W. M. Kwiatek \\ Institute of Nuclear Physics, \\ Polish Academy of Sciences, \\ Radzikowskiego 152, 31-342 Kraków, Poland
}

\section{A. Banas $(\bowtie) \cdot K$. Banas}

Singapore Synchrotron Light Source (SSLS),

National University of Singapore,

5 Research Link, Singapore 117603, Singapore

e-mail: slsba@nus.edu.sg

M. Gajda · T. Cichocki

Department of Histology,

Collegium Medicum,

Jagiellonian University,

Kopernika 7,

31-034 Kraków, Poland

B. Pawlicki

Gabriel Narutowicz Hospital,

Prạdnicka 37,

31-202 Kraków, Poland emission (micro-SRIXE). Special attention was paid to examine the relationship between the earlier-mentioned disorders and changes in relative concentrations of $\mathrm{S}, \mathrm{K}, \mathrm{Ca}$, $\mathrm{Fe}, \mathrm{Cu}$, and $\mathrm{Zn}$. Applying the image-processing program ImageJ enabled us to select the areas of interest from twodimensional maps of various prostate samples according to the histopathologist's evaluation. Detailed analysis of micro-SRIXE spectra based on multivariate methods shows significant differences between elemental concentrations in inflammatory cells, PIN lesions, and cancerous tissues, which confirms that this method can be used to distinguish various pathological states in prostate tissues. Information obtained in this way may provide better understanding of the biochemistry of unhealthy prostate tissues, thus opening the way to find new medicines/treatments to prevent or slow down some harmful intracellular processes.

Keywords Prostate cancer - Inflammation - Prostatic intraepithelial neoplasia - Microbeam synchrotronradiation-induced X-ray emission · ImageJ

\section{Introduction}

The prostate is a muscular, walnut-sized gland that surrounds part of the urethra, the tube that transports urine and sperm out of the body. A gland is a group of cells that secrete chemicals that act on or control the activity of other cells or organs.

The prostate gland is the most common site of neoplastic disorders in men. Prostate cancer is one of the most commonly diagnosed and potentially devastating cancers in men throughout the world. Prostate cancer is characterized by unpredictable biologic behavior, and a long latency before diagnosis. Most pathologists grade prostate 
cancer according to the Gleason score [2], which assigns a grade (1-5) based on how the cancerous cells look compared with normal prostate cells. The higher the Gleason score, the more likely it is that the cancer will grow and spread rapidly [3].

Sometimes, when a pathologist looks at prostate cells under a microscope, they do not look cancerous, but they are not quite normal either. These results are often reported as "suspicious" and fall into one of two categories: inflammatory cells or prostatic intraepithelial neoplasia (PIN). The pathogenesis of inflammatory cells and PIN lesions is still under investigation, but these structures are mentioned as primary factors leading to cancerogenesis. Generally it is known that cancerogenesis is a process which normally begins several years before it is detected and causes side effects; in other words, prostate cancer cells do not suddenly spring into existence fully formed. Inflammatory cells are one of the major sources of reactive oxygen and nitrogen species. These compounds are released in attempts to eradicate or perceive infectious organisms [4].

Repeated bouts of immune-mediated oxidant and nitrogenous injury over many years are suspected to play a major role in the pathogenesis of cancer in a number of organ systems, including the stomach, colon, and liver [5]. Population-based studies have shown that susceptibility to cancer increases when tissues are chronically inflamed [6-8].

Currently, there are suggestive but not definitive data on the relation between inflammation of the prostate and the development of malignancy. Results from observational studies have suggested that a history of clinical prostatitis (an inflammation of the prostate gland) may be associated with increased risk of the development of prostate cancer $[9,10]$. However, there are a couple of potential reasons why prostate cancer may be found more often in men with prostatitis. Patients with prostatitis are often under the care of a urologist, where a blood test for prostate cancer marker, known as prostate-specific antigen, may be obtained and may lead to a prostate biopsy. The prostate biopsy might show an incidental cancer. If these men did not have prostatitis, they may not have gone to a urologist and therefore may never been tested for prostate cancer in the first place. Also, cells in an inflamed prostate sometimes show changes suggestive of a precancerous state. However, it is not clear that the prostatitis causes these cellular changes [11].

Most solid tumors (such as prostate cancer) contain many nonmalignant cells, including immune cells and blood-vessel cells that are important in inflammation. But the crucial molecular pathways that permit communication between abnormally growing cancer cells and the inflammatory cells remain unknown [8].

The term PIN was selected at a conference in 1989 from a whole variety of other names for the same condition. PIN refers to architecturally benign prostatic acini and ducts lined by atypical cells, which share morphological, histochemical, immunohistochemical, and genetic changes with cancer. However, PIN lacks invasion of the basement membrane of the prostatic glands [12-14]. PIN is regarded as a precursor lesion to prostate cancer or a marker signaling the vulnerability of the epithelium to neoplastic transformation [15]. Its role as the preinvasive stage of cancer was recently confirmed conclusively in two separate mouse models [16, 17]. The finding of PIN in prostate tissues suggests that prostatic adenocarcinoma may also be present (about 50\% of cases). According to the literature $[15,18]$, patients with an initial diagnosis of high-grade PIN are at greater risk of subsequent prostatic adenocarcinoma than those with diagnosis of a benign lesion.

Figure 1 shows an example of chronic inflammatory cells and PIN lesions, respectively. Both inflammatory cells and PIN lesions do not form tumor mass. Inflammatory cells contain mainly lymphocytes, which have small, round, very darkly staining nuclei and little surrounding cytoplasm, whereas PIN is characterized by abnormal cells with enlargement of nuclei and nucleoli in the lining of the prostate ducts [19-21].

The importance of early and accurate diagnosis and prognosis of prostate cancer has prompted a search for better markers focused on the molecular mechanisms underlying tumor behavior.

The histological analysis of tissue samples by focusing on the bulk morphological features lacks quantitative accuracy and gives no account of the biochemical background of the changes that occur during different disorders in prostate tissues. For those reasons we decided to asses inflammatory cells, PIN lesions, and cancerous tissues by taking into account the concentration of different elements present in these structures. Special attention was paid to examining the relationship between the earlier-mentioned disorders in prostate tissues and $\mathrm{S}, \mathrm{K}, \mathrm{Ca}, \mathrm{Fe}, \mathrm{Cu}$, and $\mathrm{Zn}$ concentrations. These elements were selected as an example of essential constituents in normal human homeostasis. It is believed that any major health disturbances can be manifested by changes in their normal concentrations.

$\mathrm{S}, \mathrm{K}$, and $\mathrm{Ca}$ are the most abundant minerals in the human body. Every living cell inside the body contains $\mathrm{S}$ and it is also a component of amino acids, which are seen as the building blocks of the body. Normal body function depends on tight regulation of $\mathrm{K}$ concentrations both inside and outside cells [22]. About $99 \%$ of the $\mathrm{Ca}$ in the body is found in bones and teeth, whereas the other $1 \%$ is found in the blood and soft tissue. Ca levels in the blood and fluid surrounding the cells (extracellular fluid) must be maintained within a very narrow concentration range for normal physiological functioning [23]. 
Fig. 1 a Inflammatory cells and b prostatic intraepithelial neoplasia (PIN) lesions of the prostate tissues

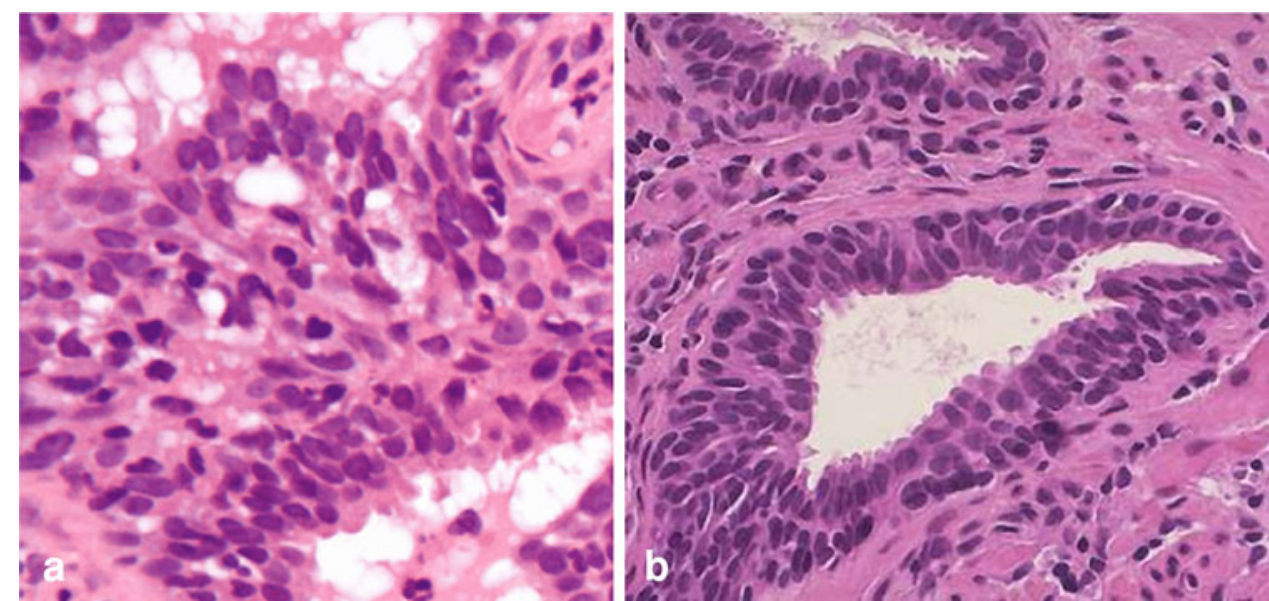

Trace elements are required in small concentrations as essential components of biological enzyme systems or of the structural portion of biologically active constituents. $\mathrm{Cu}, \mathrm{Fe}$, and $\mathrm{Zn}$ [24] play their most important role as cofactors in enzymes. Additionally, $\mathrm{Fe}$ is an important constituent of succinate dehydrogenase as well as a part of the hemoglobin heme, myoglobin, and the cytochromes. $\mathrm{Zn}$ is involved in carbonic acid (carbonic anhydrase) and in alcohol (alcohol dehydrogenase) formation and in proteolysis (carboxypeptidase, leucine aminopeptidase, etc.). $\mathrm{Cu}$ is present in many enzymes involved in oxidation (tyrosinase, ceruloplasmin, amine oxidase, etc.).

On the other hand, any unregulated level of transition metal ions $\left(\mathrm{Fe}^{2+}, \mathrm{Cu}^{2+}\right)$ has the potential to catalyze and generate hydroxyl radicals $(\mathrm{OH} \cdot)$ from superoxide and hydrogen peroxide via the Fenton reaction. The highly reactive hydroxyl radicals subsequently cause lipid peroxidation and degradation of other macromolecules, leading to cell damage or death [25-27].

In this work, the synchrotron-radiation-induced X-ray emission (SRIXE) method was used for quantitative elemental analysis of inflammation, PIN lesions, and cancerous prostate tissues. Usage of the image-processing program ImageJ enabled us to isolate the areas of interest from two-dimensional (2D) maps of various prostate samples. The data obtained were then processed with the use of multivariate statistical methods.

Among physical techniques for the multielemental composition analysis of biological objects, most appropriate seems to be SRIXE owing to its extended elemental coverage, superior sensitivity, and rapid analytical capabilities. Experiments can be done in air. Sample structures are preserved during experiments owing to the lower thermal damage compared with charged particle excitation-so SRIXE can be considered as a not destructive method. Development of focusing optical elements for $\mathrm{X}$-rays and the high brightness of synchrotron radiation allow the creation of beams of micrometer size with high intensity. Only a microfocused beam is useful in analysis of microspots of a size comparable to the cell diameter. Recently microbeam SRIXE (micro-SRIXE) has been widely used in research, leading to a better understanding of different processes occurring in cells by analyzing the concentration of selected elements in biological samples [28-31].

The main goal of this work was to find the answer to the question of whether the earlier-mentioned elements $(\mathrm{S}, \mathrm{K}$, $\mathrm{Ca}, \mathrm{Fe}, \mathrm{Cu}$, and $\mathrm{Zn}$ ) are able to help in distinguishing between inflammatory cells, PIN lesions, and cancerous tissues in prostate samples. By combing a new computerbased method for image analysis which is able to identify very small structures existing in prostate tissues (inflammatory cells and PIN lesions) with detailed analysis of micro-SRIXE spectra based on multivariate methods, we proved they can help.

Nowadays, very often scientists obtain experimental results with many variables and it seems impossible to draw any sensible conclusion without proper data reduction. Multivariate statistical techniques help researchers to find the relationships and discover the most important factors and variables in their systems. In this investigation we used linear discriminant analysis.

\section{Materials and methods}

\section{Samples}

The samples analyzed in experiments were taken during operations related to urological disorders from three patients at the Department of Urology, City Hospital im. Narutowicza, Kraków, Poland. Data from clinical reports are presented in Table 1. For this study only three patients were selected because in the prostate tissues provided for 
Table 1 Clinical report for patients who had undergone prostatectomies

\begin{tabular}{lllll}
\hline & Age (years) & Diagnosis & Gleason score & Clinical stage \\
\hline Patient 1 & 65 & Prostate adenocarcinoma & $7(4+3)$ & pT3b \\
Patient 2 & 72 & Prostate adenocarcinoma & $5(2+3)$ & pT2c \\
Patient 3 & 66 & Prostate adenocarcinoma & $4(2+2)$ & pT2a \\
\hline
\end{tabular}

SRIXE analysis the coexistence of cancerous (CA), inflammatory (INFL), and PIN groups was found.

First, samples were frozen in liquid nitrogen to stop effectively any biological activities, including the biochemical reactions which could lead to unwanted alteration of the concentrations of all elements inside cells. Liquid nitrogen is a good refrigerant and is widely used in the cryopreservation of blood, reproductive cells (sperm and egg), and other biological samples and materials.

After freezing, prostate materials were cut into 14- $\mu$ mthick sections by using a cryomicrotome (at $-30{ }^{\circ} \mathrm{C}$ ) and two kinds of samples were prepared (total number of samples 60). For micro-SRIXE experiments, tissue layers were placed on 2.5- $\mu$ m-thick Mylar foil. Adjacent sections were mounted on a poly(L-lysine)-coated slide, stained routinely with hematoxylin and eosin, and then examined by an experienced histopathologist. From these studies certain areas with inflammatory cells, PIN lesions, and cancerous cells were selected for further physical analyses.

After sample preparation, detailed documentation of samples was made by using an Olympus BX-50 microscope. No cell damage which would happen during the freezing procedure was observed in sample patterns.

\section{Measurements}

Measurements were performed at beamline L at HASYLAB at DESY (Hamburg, Germany). The microprobe setup at beamline $\mathrm{L}$ is a powerful tool for simultaneous multielement analysis of microsamples [32-34].

During the experiments the energy of the exciting beam was set to $17 \mathrm{keV}$. A polycapillary was used to achieved a focused beam; its size on the sample was approximately $15 \mu \mathrm{m}$, which is of the order of a cell diameter. The sample was fixed on a remote-controlled stage equipped with highprecision stepping motors allowing for micrometer movements in $x y z$ directions, just in front of the polycapillary at an angle of $45^{\circ}$ with respect to the incoming beam. During the experiments, the $2 \mathrm{D}$ scans were made on selected areas of prepared tissues samples to obtain the distributions of various elements. The region for the scan was carefully chosen according to the histopathological assessment of the sample. The typical size of the scanned area was around $450 \times 450 \mu \mathrm{m}^{2}$; the scans were done with a step size of $15 \mu \mathrm{m}$ in each direction. From each spot in the analyzed area, a typical X-ray fluorescence spectrum was taken. The acquisition time of a single spectrum was set to $10 \mathrm{~s}$. The measurements were performed in air atmosphere and at room temperature. The characteristic X-ray lines were collected with the use of a conventional high-purity Ge $\mathrm{X}$-ray detector (with energy resolution of $120 \mathrm{eV}$ at $5.89 \mathrm{keV}$ ) positioned at $90^{\circ}$ to the incoming linear polarized X-ray beam and placed in the storage ring plane to minimize the intensity of the scattering X-rays.

Data analysis was done by means of appropriate software, first AXIL for the evaluation of X-ray fluorescence spectra, then ImageJ for image processing, and finally the $\mathrm{R}$ statistical platform for statistical evaluation of the results obtained.

\section{Results and discussion}

The distribution images (mappings) of certain elements were obtained by detailed analysis of each spectrum involving background deduction, normalization to the storage ring beam current, fitting the measured spectra with suitable mathematical functions, and integration of the area under the peak of $\mathrm{K}_{\alpha}$ corresponding to the chosen element over the region of interest. Detailed description of the procedure for preparation of maps can be found in our previous articles [35, 36].

In this article we use the term "elemental concentration" for the peak area expressed in arbitrary units assuming that its value is proportional to the real concentration of the selected element.

Analysis of the different structures of prostate tissues samples, especially small ones such as inflammatory cells and PIN lesions, by comparing the histological image with the map of distribution of the chosen element is an extremely laborious and time-consuming process.

For the first time, we used a semiautomated computerized method to obtain information about accumulation of various elements by inflammatory cells and PIN lesions. Usage of a plug-in for the public domain image-analysis program ImageJ, which runs on all standard operating systems (Windows, Mac OS, and Linux) [37, 38], enabled us to identify and analyze hematoxylin-stained nuclei in the digital image of routine immunohistochemical slides.

The first step in this process was the separation of the original image into pure hematoxylin and eosin images, which is presented in Fig. 2. The pure hematoxylin image 
Fig. 2 Separation of the original image presented in Fig. 1b into pure hematoxylin (a) and eosin (b) images

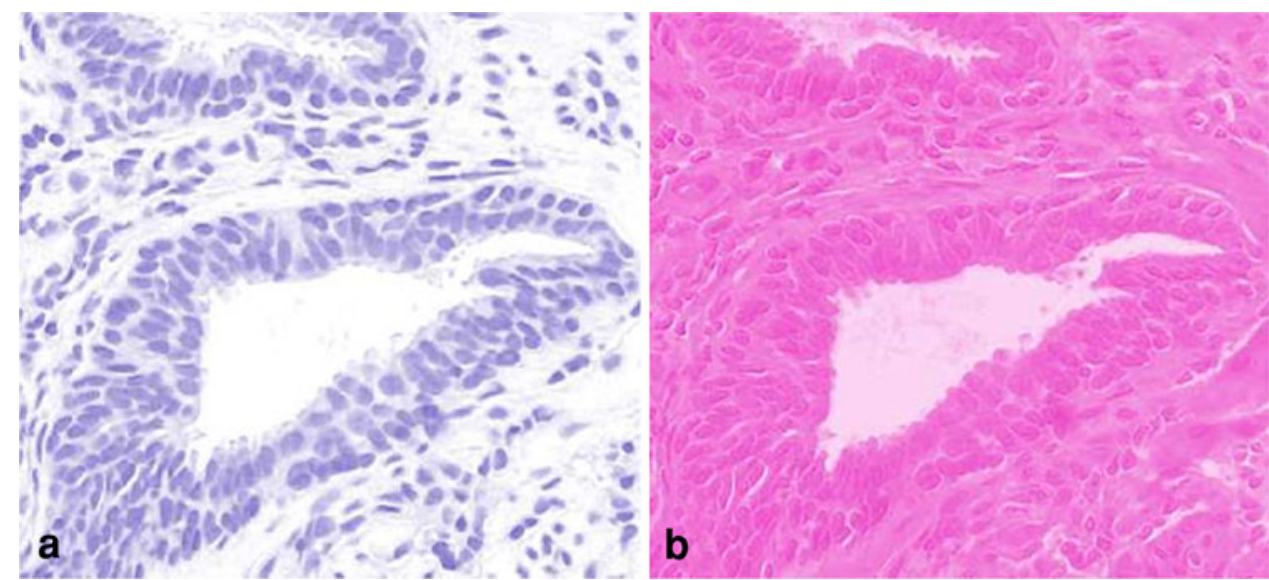

was used for further analysis because it is well known that hematoxylin is the best indicator of nuclei. In this way, the hematoxylin image served as an indicator of PIN lesions and inflammatory cells.

Using the hematoxylin image, we created a digital mask, which enabled us to analyze the respective regions of interest. Each area of the mask was outlined and numbered automatically. Small particles or stains not clearly identifiable were excluded automatically from analysis. An example of a mask used in the method mentioned earlier, without numbers of areas to achieve good visibility, is presented in Fig. 3a.

The next step was to overlap the mask with the map of the distribution of chosen element, which is shown in Fig. 3c. Different statistical parameters for every region of interest (e.g., mean value, standard deviation, maximum and minimum value) were calculated during the overlapping process and recorded in the file.

Statistical analysis and graphic presentation of data were done in the R platform (version 2.10) [39].

Figure 4 shows the kernel density estimations of the elemental concentrations (peak areas) for the elements analyzed- $\mathrm{S}, \mathrm{K}, \mathrm{Ca}, \mathrm{Fe}, \mathrm{Cu}$, and $\mathrm{Zn}-$ separately for the three categories (CA, INFL, and PIN) obtained with the package ggplot2 [40]. As shown, most distributions are broad and asymmetric. Several factors may contribute to the wide concentration range of the results, such as differences in diet, hormonal status, genetics, drug administration, and especially the differences between stages of abnormality.

As one can see, it is very difficult to spot the real disparity between the concentrations of most elements in the analyzed groups. There are some trends, but generally these distributions overlap and do not allow proper classification.

For S, being the third most abundant element in the body based on percentage of total body weight, its peak area distributions seem to be very alike in terms of maximum density values and width for the CA and PIN groups, which can be related to the similar role which $\mathrm{S}$ plays in the biochemistry for these two groups. S-containing amino acids contribute substantially to the maintenance and integrity of cellular systems by influencing cellular redox state and cellular capacity to detoxify toxic compounds, free radicals, and reactive oxygen species. Methionine and cysteine are the two primary S-containing amino acids in
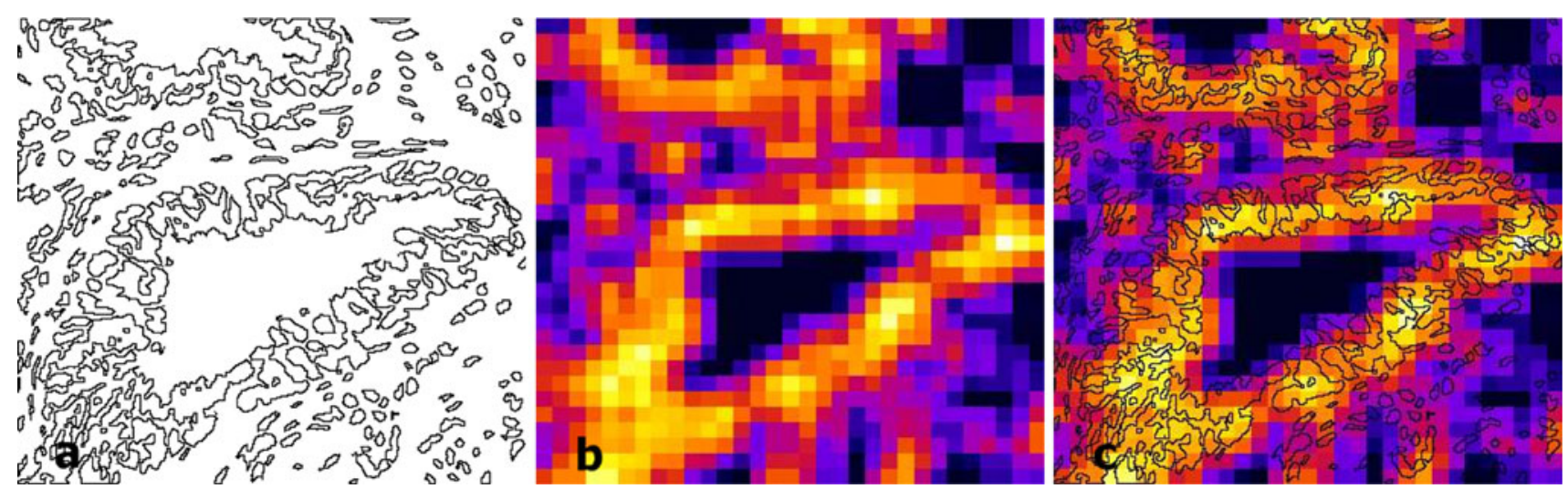

Fig. 3 a Mask made from the pure hematoxylin image, b map of S distribution, and $\mathbf{c}$ overlapping mask with map of S distribution 
mammals. Methionine as an essential amino acid plays a major role in DNA synthesis and in carbon metabolism. Some cancer cell primary cultures and cell lines express an unusual dependence on methionine for growth [41]. The metabolism of S-containing amino acids has been linked to several key aspects of human health and cellular function [42], and maybe the lower median for $S$ concentration in the INFL group (Fig. 4a) in comparison with the values for the CA and PIN groups is connected with "weaker" $\mathrm{S}$ activity for the INFL group.

The kernel density estimation for K (Fig. 4b) depicts a trend very similar to that in the $S$ case for all analyzed groups. $\mathrm{K}$ is the most abundant cation inside human cells (intracellular), and as such contributes critically in numerous important ways to their optimal functioning. Among other metabolic functions, $\mathrm{K}$ plays a role in the synthesis of proteins and in the biochemical transformations required for carbohydrate metabolism. The activity of $\mathrm{K}$ channels has been related to cell cycle progression, oncogenesis, and proliferation, and although the precise mechanism involved has not been explicated, several hypotheses have been suggested [43]. K efflux through $\mathrm{K}$ channels induces hyperpolarization and changes in cell volume; the latter according to some studies is closely related to cell proliferation [44, 45]. Higher K concentration with respect to median values was found for CA and
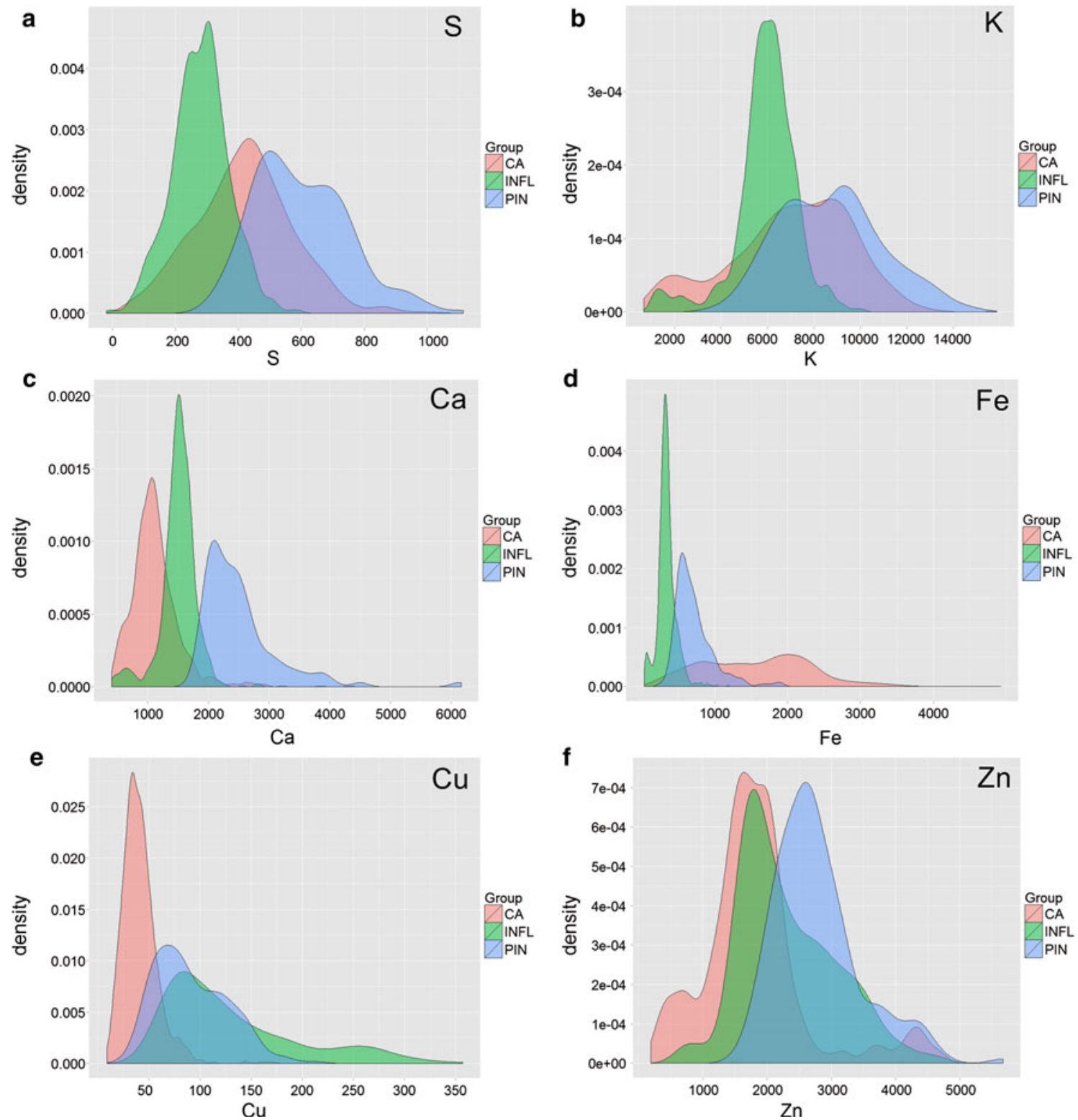

Fig. 4 Distribution of peak area for $\mathbf{a} \mathrm{S}, \mathbf{b} \mathrm{K}, \mathbf{c ~ C a}, \mathbf{d ~ F e}, \mathbf{e ~ C u}$, and $\mathbf{f} \mathrm{Zn}$ for analyzed groups: red cancerous (CA), green inflammatory (INFL), blue PIN 
PIN groups, which may indicate involvement of this element in rapid proliferation. Undoubtedly, $\mathrm{K}$ distribution behaviors for all groups may point to similar processes occurring in the CA and PIN groups but different processes for the INFL group.

$\mathrm{Ca}$ ions play a central role in the regulation of many aspects of cell physiological processes. Control of muscle contraction or neurotransmitter release is an obvious example, but $\mathrm{Ca}$ homeostasis has also been demonstrated to be implicated in processes such as cancer growth, cell cycle progression [46, 47], cell migration [48], angiogenesis [49], apoptosis [50], and proliferation [51]. In our analysis, peak area distributions for $\mathrm{Ca}$ allowed us to make a clear distinction among all analyzed groups: the different types of prostate abnormalities can be characterized by their own Ca signature. According to the literature [52], each cellular phenotype, whether normal or pathological, is characterized by a particular " $\mathrm{Ca}^{2+}$ signature" reflecting the kinetics, amplitude, and subcellular localization of the $\mathrm{Ca}^{2+}$ signals.

In the case of Fe (Fig. 4d), the highest median value was found for the CA group and the lowest was found for the INFL group. This result can be related to the fact that malignant tissue utilizes larger amounts of this element because of its high cell concentration, rapid cell division, and more active and complex metabolism. Fe is essential for the normal physiological functions in humans-during evolution it was selected as a carrier of oxygen inside the body. However, Fe can work as a double-edged sword, and excess Fe leads to a risk of cancer or of general mortality [53]. Mechanisms whereby $\mathrm{Fe}$ may act in carcinogenesis are generation of reactive oxygen species, facilitation of tumor growth, and modification of the immune system [54]. Fe may also be a limiting nutrient for the growth and replication of a cancer cell [55].

$\mathrm{Cu}$ is an essential trace element that plays a central role in the biochemistry of every living organism in conserved processes, such as respiration and in highly specialized ones such as protein modifications. The unique electronic structure of $\mathrm{Cu}$ allows it to serve as a cofactor in redox reactions of enzymes such as superoxide dismutases involved in the detoxification of reactive oxygen species [56]. In our analysis, higher $\mathrm{Cu}$ concentrations were found for PIN and INFL groups, which may be connected with the high activity of the antioxidant defense system for these groups and reduction in the defensive capability of cells for the CA group.

$\mathrm{Zn}$ is the second most abundant transitional metal ion in human body, and is essential for the proper function for different enzymes and for tight control of gene expression [57]. It contributes to a number of important processes, including cell growth, replication, and osteogenesis [58, 59]. $\mathrm{Zn}$ has a significant impact on DNA as a component of chromatin structure and DNA replication and transcription. $\mathrm{Zn}$ is a component of more than 3,000 $\mathrm{Zn}$-associated transcription factors, and more than 300 enzymes, including $\mathrm{Cu} / \mathrm{Zn}$ superoxide dismutase and several proteins involved in DNA repair [60, 61]. The $\mathrm{Zn}$ concentration distributions presented in Fig. $4 \mathrm{f}$ are characterized by two relatively narrow and shifted peaks for the CA and PIN groups, which can be related to rather different $\mathrm{Zn}$ metabolism within these tissues, whereas for the INFL group the broad $\mathrm{Zn}$ distribution may point to various metabolic processes such as those present in both the PIN group and the CA group.

As part of our analysis, the two-sample nonparametric Wilcoxon rank sum test (equivalent to the Mann-Whitney test) was performed. Although calculated $p$ values (less than 0.05) indicate statistically significant differences for the median of all analyzed variables $(\mathrm{S}, \mathrm{K}, \mathrm{Ca}, \mathrm{Fe}, \mathrm{Cu}$, and $\mathrm{Zn}$ ) between all compared pairs (CA-PIN, CA-INFL, PIN-INFL), the specificity of these distributions (not normal) makes it impossible to claim that the analyzed elements could help in making a clear distinction between the prostate disorders taken into consideration.

The next step was the search for correlations at two elemental concentrations for given points. This method of presentation (Fig. 5) revealed some interesting trends and
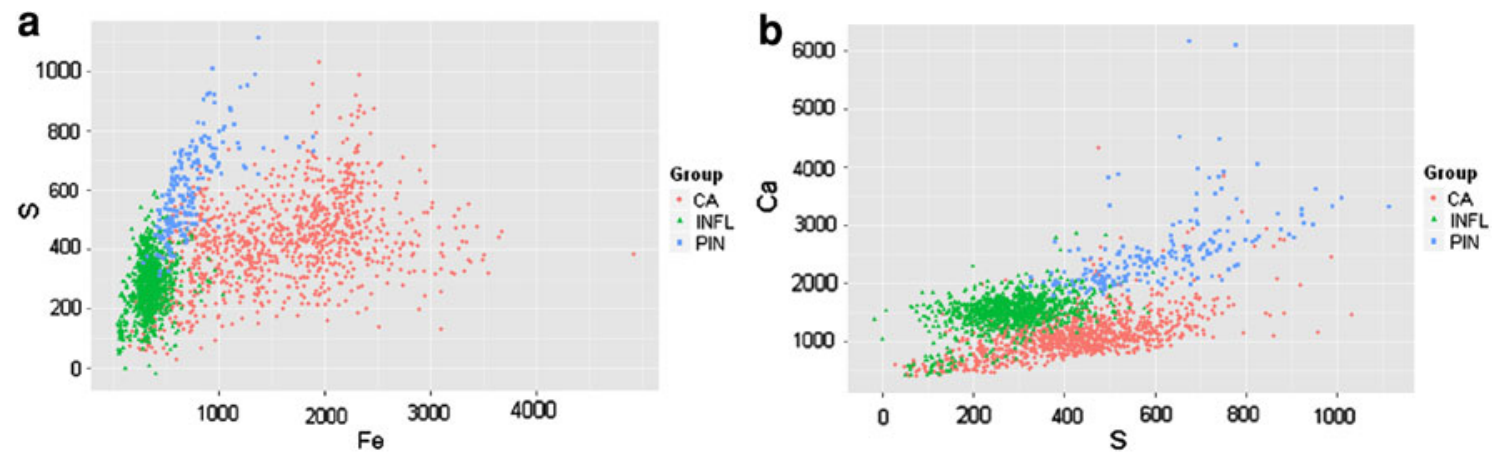

Fig. 5 Scatter plot for two elements a $\mathrm{Fe}$ and $\mathrm{S}$ and $\mathbf{b} \mathrm{S}$ and $\mathrm{Ca}$ for analyzed groups: red CA, green INFL, blue PIN 


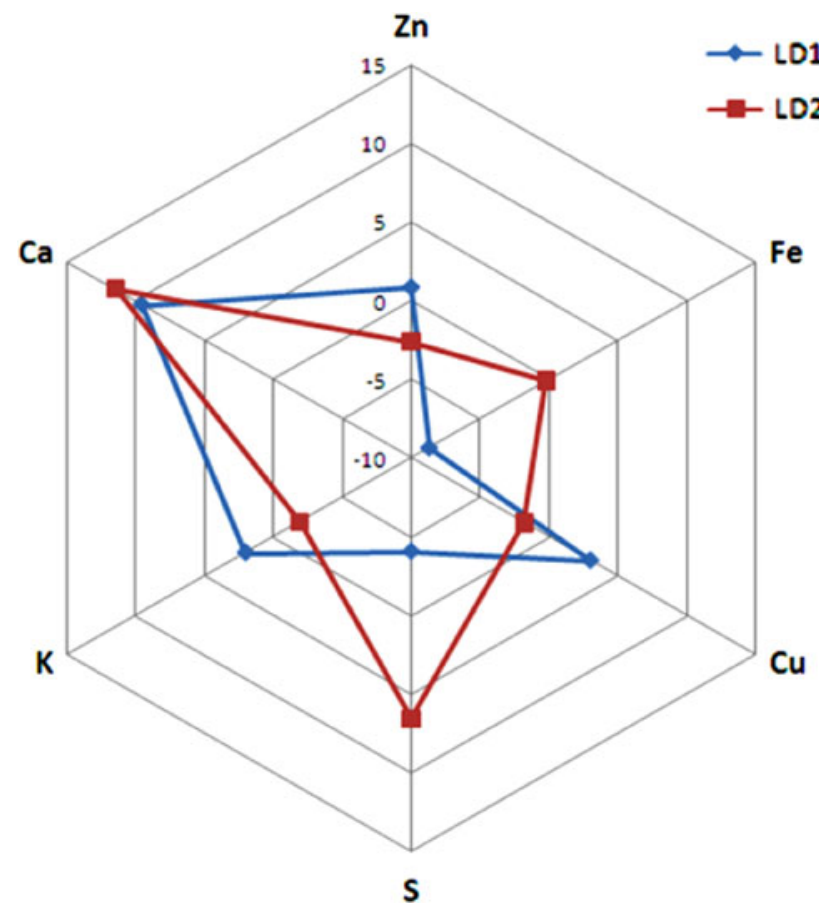

Fig. 6 Radar plot of eigenvectors (canonical discriminant coefficients) showing the importance of the initial variables in the first linear discriminant function (LDl) (blue) and the second linear discriminant function $(L D 2)$ (red)

shows the clustering of the data belonging to different categories. However, unambiguous identification in many cases is still not possible.

To improve the performance in distinguishing among the three analyzed groups, we decided to use linear discriminant analysis and took into account the concentrations of more than two elements at the same time. Statistical analysis was done with the packages Rattle [62] and MASS [63] in the R environment. The concentrations of all six elements $(\mathrm{S}, \mathrm{K}, \mathrm{Ca}, \mathrm{Fe}, \mathrm{Cu}$, and $\mathrm{Zn}$ ) were included in computing the discriminant functions. All data were rescaled to the interval from 0 to 1 . All cases were a priori classified into one of the categories CA, INFL, or PIN.

The multivariate technique used gave as the output discriminant functions that are a linear combination of the initial variables (the concentrations of six elements in our case) in the form of canonical discriminant coefficients (eigenvectors). To illustrate which concentrations play the most important role in both discriminant functions, we used a radar plot (Fig. 6). The bigger the absolute value of the coefficient, the more important is the respective concentration for the discriminant function. One can easily check that for the first linear discriminant function (LD1) the most important concentrations are those of $\mathrm{Fe}$ and $\mathrm{Ca}$, whereas for the second linrear discriminant function (LD2) the concentrations of $\mathrm{Ca}$ and $\mathrm{S}$ play the main role.

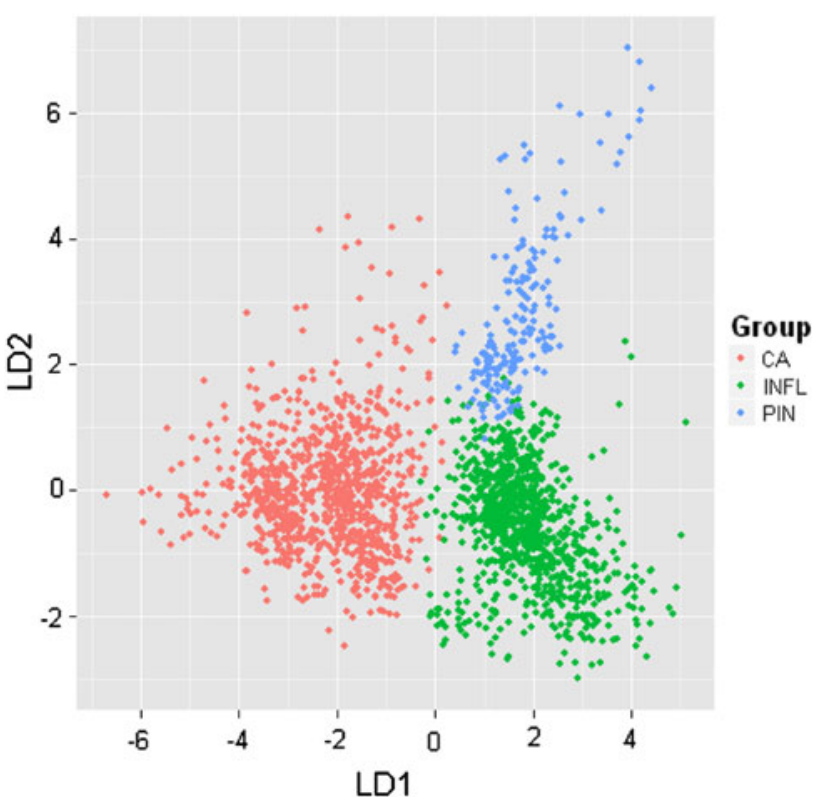

Fig. 7 Scatter plot of the data in calculated variables space (LD2 vs. LD1) showing good clustering for the different groups: red CA, green INFL, blue PIN

Table 2 Summary of the cross-validation analysis (number of cases classified to the respective groups)

\begin{tabular}{lrrrr}
\hline Category & \multicolumn{2}{l}{ Category } & \multirow{2}{*}{ Total number of cases } \\
\cline { 2 - 4 } & CA & INFL & PIN & \\
\hline CA & 970 & 5 & 14 & 989 \\
INFL & 3 & 984 & 4 & 991 \\
PIN & 0 & 29 & 165 & 194 \\
& & & & 2,174 \\
\hline
\end{tabular}

$C A$ cancerous, INFL inflammatory, PIN prostatic intraepithelial neoplasia

Figure 7 shows the scatter plot of the data in calculated variables space (LD2 vs. LD1), showing very good clustering for the different groups. One can also see that differentiation between the CA group and the rest of the data is obtained thanks to LD1 (projection of the data points to the horizontal axis). LD2 allows one to distinguish between the INFL group and the PIN group (projection to the vertical axis).

The leave-one-out cross-validation procedure was used as a method to assess the accuracy of the predictions. Observations were left out one at a time, the model was fitted to the remaining data, and a prediction was made for the observation omitted. Table 2 summarizes the results of this analysis.

This gives correct prediction of $97.65 \%$ for the whole data set $(98.1 \%$ for the CA category, $99.3 \%$ for the INFL category, and $85.1 \%$ for the PIN category). 


\section{Conclusions}

There is a continuous range of identifiable situations related to prostate cancer-from the very first biochemical event or mutation that leads to the development of the very first malignant prostate cancer cell right through to the extensive growth of bone metastases; inflammatory cells and PIN lesions may well be the first of these situations that a pathologist can actually see under the microscope.

Our results confirm that the linear discriminant analysis of elements such as $\mathrm{S}, \mathrm{K}, \mathrm{Ca}, \mathrm{Fe}, \mathrm{Cu}$, and $\mathrm{Zn}$, commonly found in prostate tissues can be used to differentiate prostate samples according to their histological classifications. These elements can be also treated as valuable tracers for the identification of pathological stages in prostate tissues. Further detailed analyses are necessary if the exact role of these elements in the structural and functional changes produced by the disease is to be understood. Differences in the concentrations of the analyzed elements among the three groups may be associated with the physiological processes occurring in the cells, such as proliferation, differentiation, and apoptosis, sometimes leading to many malignant events and being the first steps at the beginning of life-threatening diseases. The changes in the concentrations of essential elements among different histological prostate groups may reveal the biochemical background of various disorders occurring in the gland.

To our knowledge, earlier-mentioned technique based on digital image masks was successfully used for this type of analysis for the first time. Regions of interest were automatically selected by using histological images of tissue and information about the relative concentrations of selected elements in these regions was retrieved from 2D maps. The data obtained in this way were then evaluated by means of linear discriminant analysis.

To sum up, the earlier-mentioned method based on separation of the original histological image together with $\mathrm{X}$-ray fluorescence analysis using synchrotron radiation and statistical processing of the data by linear discriminant analysis seems to be an appropriate technique to obtain accurate information about different structures in prostate tissue samples. The "tools" used can be regarded as complementary techniques generating a synergetic outcome in the form of valuable and accurate results.

The high predictive adequacy of the linear discriminant analysis obtained in this pilot study points out that this approach could be used as a rapid diagnostic test applied to some elements commonly found in a small sample of excised prostate tissues (as biopsies), adding one more useful tool to aid in the diagnosis or prognosis of patients with prostate disorders. The use of this method could enable the classification of tissues representing different stages of prostate disorder cases (Gleason score 1-5 in the case of prostate cancer) in different groups and also application of these results to unknown cases.

Information gathered in this way may provide a better understanding of the processes turning noncancerous tissues into cancerous ones. However, it is necessary to consider our results as a pilot study before potential largescale investigation of the elemental composition of biological samples. Our analysis is an attempt to answer the fundamental question: what is the origin of all these prostate diseases? If we knew the answer to that question, then effective measures could be developed to prevent cancer and thus conquer the second leading cause of cancer death among men. Maybe relative changes in the concentrations of selected elements could be regarded as additional markers which could increase the sensitivity and specificity of prostate cancer detection and also aid in the therapy selection for treatment of the disease.

Acknowledgments This work was supported by the European Community-Research Infrastructure Action under the Sixth Framework Programme "Structuring the European Research Area" (through the Integrated Infrastructure Initiative "Integrating Activity on Synchrotron and Free Electron Laser Science"); contract RII3-CT2004-506008, HASYLAB project II-04-79EC. This study was partially supported by the Sixth Framework Programme of the European Commission: project "Studies on Cellular Response to Targeted Single Ions Using Nanotechnology" (CELLION, MRTN-CT-2003503923).

Open Access This article is distributed under the terms of the Creative Commons Attribution Noncommercial License which permits any noncommercial use, distribution, and reproduction in any medium, provided the original author(s) and source are credited.

\section{References}

1. Haggman MJ, Macoska JA, Wojno KJ, Oesterling JE (1997) J Urol 158:12-22

2. Gleason DF (1966) Cancer Chemother Rep 50:125-128

3. Gleason DF (1977) In: Tannenbaum M (ed) Urologic pathology: the prostate. Lea and Febringer, Philadelphia, pp 171-197

4. De Marzo AM, Meeker AK, Zha S, Luo J, Nakayama M, Platz EA, Isaacs WB, Nelson WG (2003) Urology 62:55-62

5. Ames BN, Gold LS, Willett WC (1995) Proc Natl Acad Sci USA 92:5258-5265

6. Balkwill F, Mantovani A (2001) Lancet 357:539-545

7. Coussens LM, Werb Z (2002) Nature 420:860-867

8. Balkwill F, Coussens LM (2004) Nature 431:405-406

9. Dennis LK, Lynch CF, Torner JC (2002) Urology 60:78-83

10. Kesarwani RC, Gupta A, Kumar V (2003) Indian J Surg 65:269-272

11. Molimard B, Camparo P, Desfemmes FR, Durand X, Haus R, Deligne E, Houlgatte A, Compérat E (2010) Prog Urol 20:508-514

12. Epstein JI, Herawi MJ (2006) Urology 175:820-834

13. Bostwick DG, Qian J (2004) Mod Pathol 17:360-379

14. Bostwick DG, Norlén BJ, Denis L (2000) Scand J Urol Nephrol Suppl 205:1-2 
15. Merrimen JL, Jones G, Walker D, Leung CS, Kapusta LR, Srigley JR (2009) J Urol 182:485-490

16. Kasper S, Sheppard PC, Yan Y, Pettigrew N, Borowsky AD, Prins GS, Dodd JG (1998) Lab Invest 78:319-334

17. Garabedian EM, Humphrey PA, Gordon JI (1998) Proc Natl Acad Sci USA 95:15382-15387

18. Schlesinger C, Bostwick DG, Iczkowski KA (2005) Am J Surg Pathol 29:1201-1207

19. McNeal JE, Bostwick DG (1986) Hum Pathol 17:64-71

20. Dawkins HJ, Sellner LN, Turbett GR, Thompson CA, Redmond SL, McNeal JE, Cohen RJ (2000) Prostate 44:265-270

21. Shin HJ, Ro JY (1995) Yonsei Med J 36:215-231

22. Peterson LN (1997) In: O'Dell BL, Sunde RA (eds) Handbook of nutritionally essential minerals. Dekker, New York, pp 153-183

23. Weaver CM, Heaney RP (1999) In: Shils M, Olson JA, Shike M, Ross AC (eds) Modern nutrition in health and disease. Lippincott Williams \& Wilkins, Baltimore, pp 141-155

24. Ozen OA, Yaman M, Sarsilmaz MJ (2003) Trace Elem Med Biol $16: 119-122$

25. Zowczak M, Iskra M, Paszkowski J, Manczak M, Torlinski L, Wysocka E (2001) J Trace Elem Med Biol 15:193-196

26. Rice-Evans C, Burdon R (1993) Prog Lipid Res 32:71-110

27. McCord JM (1998) Semin Hematol 35:5-12

28. Chwiej J (2010) J Trace Elem Med Biol 24:78-88

29. Bohic S, Simionovici A, Ortega R, Heymann D, Schroer C, Snigirev A (2001) Nucl Instrum Methods B 181:728-733

30. Kolmogorov Y, Kovaleva V, Gonchar A (2000) Nucl Instrum Methods A 448:457-460

31. Poletti ME, Gonçalves OD, Pérez CA, Magalhães SD (2004) Radiat Phys Chem 71:975-976

32. Deutsches Elektronen-Synchrotron DESY (2011) HASYLAB homepage. http://www.hasylab.de

33. Falkenberg G, Clauss O, Swiderski A, Tschentscher T (2001) X-Ray Spectrom 30:170-173

34. Al-Ebraheem A, Farquharson MJ, Ryan E (2009) Appl Radiat Isot $67: 470-474$

35. Banas A, Banas K, Falkenberg G, Kwiatek WM (2006) Acta Phys Pol A 109:323-328

36. Banas A, Kwiatek WM, Banas K, Gajda M, Pawlicki B, Cichocki $\mathrm{T}$ (2010) J Biol Inorg Chem 15:1147-1155
37. Rasband WS (1997-2006) ImageJ. US National Institutes of Health, Bethesda

38. Abramoff MD, Magelhaes PJ, Ram SJ (2004) Biophotonics Int $11: 36-42$

39. R Development Core Team (2009) R: a language and environment for statistical computing

40. Wickham H (2009) ggplot2: elegant graphics for data analysis. Springer, New York

41. Hoffman RM (1982) In Vitro 18:421-428

42. Townsend DM, Tew KD, Tapiero H (2004) Biomed Pharmacother 58:47-55

43. Pardo LA (2004) Physiology 19:285-292

44. Wang Z (2004) Pflugers Arch 448:274-286

45. Patel AJ, Lazdunski M (2004) Pflugers Arch 448:261-273

46. Means AR (1994) FEBS Lett 347:1-4

47. Short AD, Bian J, Gosh TK, Waldron RT, Rybak SL, Gill DL (1993) Proc Natl Acad Sci USA 90:4986-4990

48. Savarese DMF, Russel JT, Fatatis A, Liotta LA (1992) J Biol Chem 267:21928-21935

49. Kohn E, Allessandro R, Spoonster J, Wersto R, Liotta LA (1995) Proc Natl Acad Sci USA 92:1307-1311

50. Nicotera P, Zhivotovsky B, Orrenius S (1994) Cell Calcium $16: 279-288$

51. Berridge MJ (1995) Bioessays 17:491-500

52. Berridge MJ, Bootman MD, Roderick HL (2003) Nat Rev Mol Cell Biol 4:517-529

53. Toyokuni S (2009) Cancer Sci 100:9-16

54. Stevens RG, Jones DY, Micozzi MS, Taylor PR (1988) N Engl J Med 319:1047-1052

55. Stevens RG (1990) Med Oncol Tumor Pharmacother 7:177-181

56. Gupte A, Mumper RJ (2009) Cancer Treat Rev 35:32-46

57. Maverakis E, Fung MA, Lynch PJ, Draznin M, Michael DJ, Ruben B, Fazel N (2007) J Am Acad Dermatol 56:116-124

58. Platz EA, Helzlsouer KJ (2001) Epidemiol Rev 23:93-101

59. Chow CK (1979) Am J Clin Nutr 32:1066-1081

60. Prasad AS (1998) J Am Coll Nutr 17:542-543

61. Prasad AS, Kucuk O (2002) Cancer Metastasis Rev 21:291-295

62. Williams GJ (2009) R J 1:45-55

63. Venables WN, Ripley BD (2002) Modern applied statistics with S. Springer, New York 